\title{
ANALISIS PELAKSANAAN KESELAMATAN DAN KESEHATAN KERJA (K3) PADA PROYEK PEMBANGUNAN GEDUNG K UNIVERSITAS MUHAMMADIYAH PURWOKERTO
}

\section{THE ANALYSIS OF OCCUPATIONAL SAFETY AND HEALTH IMPLEMENTATION (OSH) ON THE CONSTRUCTION PROJECT OF K BUILDING IN UNIVERSITAS MUHAMMADIYAH PURWOKERTO}

\author{
Reszzah Maretnowati ${ }^{1}$, Amris Azizi ${ }^{2}$, Sulfah Anjarwati ${ }^{3}$ \\ ${ }^{123}$ Program Studi S1 Teknik Sipil, Fakultas Teknik dan Sains \\ Universitas Muhammadiyah Purwokerto
}

Informasi Artikel
Dikirim,
Direvisi,
Diterima,

\section{Korespondensi Penulis:}

Reszzah Maretnowati Program Studi Teknik Sipil Universitas Muhammadiyah Purwokerto

JL. K.H. Ahmad Dahlan Purwokerto, 53182

Email: reszzahmaret@gmail.com

\section{ABSTRAK}

Penelitian ini di latar belakangi oleh adanya permasalahan apakah pelaksanaan K3 pada proyek Pembangunan Gedung K Universitas Muhammadiyah Purokerto sudah terlaksana sesuai dengan SOP perusahaan. PT Krakatau Indah selaku pelaksana proyek berkomitmen melindungi pekerjanya dari kecelakaan kerja dengan berpedoman pada SOP K3 perusahaan, tujuannya untuk mengetahui apakah pelaksanaan K3 sudah terlaksana sesuai dengan SOP perusahaan. Pelaksanaan K3 wajib dipatuhi dan dilaksanakan oleh pekerja demi mencegah kecelakaan kerja. Jenis penelitian ini adalah penelitian kuantitatif menggunakan alat ukur kuesioner dengan jumlah responden 48 pekerja finishing (pemasangan kusen ACP, pengecatan, dan curtain wall). Pengolahan data hasil kuisioner menggunakan program IBM SPSS Statistics 26 dan Microsoft Excel. Hasil penelitian ini menunjukan bahwa pelaksanaan K3 pada proyek Pembangunan Gedung K Universitas Muhammadiyah Purwokerto sudah dilaksanakan sesuai dengan SOP perusahaan $(86,28 \%)$. Hasil tersebut didukung oleh beberapa faktor yaitu top management $(85 \%)$, peraturan dan prosedur K3 $(83,19 \%)$, komunikasi pekerja $(87,81 \%)$, kopetensi pekerja $(86,81 \%)$, lingkungan kerja $(87,08 \%)$, kesehatan kerja $(88,54 \%)$, dan kinerja pekerja $(85,52 \%)$.

Kata Kunci : Penerapan K3, Proyek Pembangunan Gedung K Universitas Muhammadiyah Purwokerto

\begin{abstract}
This research was motivated by the problem on of whether the Occupational Safety and Health $(\mathrm{OSH})$ on the construction project of $K$ Building in Universitas Muhammadiyah Purwokerto has been implemented base on the SOP (Standard Operating Procedure) of PT Krakatau Indah as the project manager which commits to protect the workers from work accident referring to the SOP of OSH. The purpose of this research was to find out whether the implementation of OSH was based on the SOP of the company. The Implementation of OSH has to be obeyed and done by the workers to prevent any work accident. This was quantitative research that used a questionnaire with 48 finishing workers (applying frame, painting, and curtain wall). The data analysis of the questionnaire results used IBM SPSS Statistics 26 programme and Microsoft Excel. The results showed that the OSH on the construction project of $K$ Building in Universitas Muhammadiyah Purwokerto has been implemented based on the company SOP( $86.28 \%)$. The result was supported by some factors such as top management( $85 \%)$, regulations and procedure of $\mathrm{OSH}(83.19 \%)$, workers communication $(87.81 \%)$, workers competence(86.81\%), work environment $(87.08 \%)$, occupational health $(88.54 \%)$, and
\end{abstract} workers performance $(85.52 \%)$.

Keyword : The implementation of OSH, Construction Project of K Building Universitas Muhammadiyah 


\section{PENDAHULUAN}

Pelaksanaan proyek konstruksi sangatlah rawan akan resiko kecelakaan kerja maupun penyakit akibat kerja. Adanya alat - alat kerja, material, pekerja pada area proyek, pengaruh iklim dan cuaca dapat menimbulkan resiko adanya kecelakaan kerja. Faktor lain seperti tidak mengindahkan standar keselamatan kerja atau pemilihan metode kerja yang kurang tepat juga dapat membuat resiko yang ada semakin besar.

Faktor - faktor keselamatan dan kesehatan kerja (K3) sangat berpengaruh terhadap kinerja dari sebuah proyek, sehingga harus diperhatikan dengan sungguh - sungguh. Pengabaian faktor tersebut terbukti mengakibatkan tingginya tingkat kecelakaan kerja pada proyek. Sehingga akan menambah biaya asuransi tenaga kerja dan mempengaruhi kinerja proyek. Oleh karena itu, pada saat pelaksanaan pekerjaan konstruksi diwajibkan untuk menerapkan sistem manajemen keselamatan dan kesehatan kerja (K3) di lokasi kerja dimana masalah keselamatan dan kesehatan kerja ini juga merupakan bagian dari perencanaan dan pengendalian proyek (Ervianto, 2005).

Gedung K Universitas Muhammadiyah Purwokerto yang direncakan 10 lantai memiliki tingkat resiko kecelakaan kerja yang tinggi. PT Krakatau Indah selaku kontraktor Proyek Pembangunan Gedung K Universitas Muhammadiyah Purwokerto berkomitmen melindungi setiap pekerjanya sesuai dengan target yaitu Zero Accident. Untuk mencegah kecelakaan kerja PT Krakatau Indah berpedoman kepada SOP K3 perusahaan yang diaplikasikan kepada pekerja.

\section{METODE PENELITIAN}

\subsection{Metode Pengumpulan Data}

1. Data Primer

Pengumpulan data primer dilakukan dengan menggunakan angket kuesioner yang ditunjukan kepada pekerja finishing (pekerjaan kusen ACP, pengecatan, dan curtain wall).

2. Data Sekunder

Data sekunder yang didapat yaitu SOP (Standar Operasional Prosedur) perusahaan.

\subsection{Instrumen Penelitian}

Tabel 1. Instrumen Penelitian

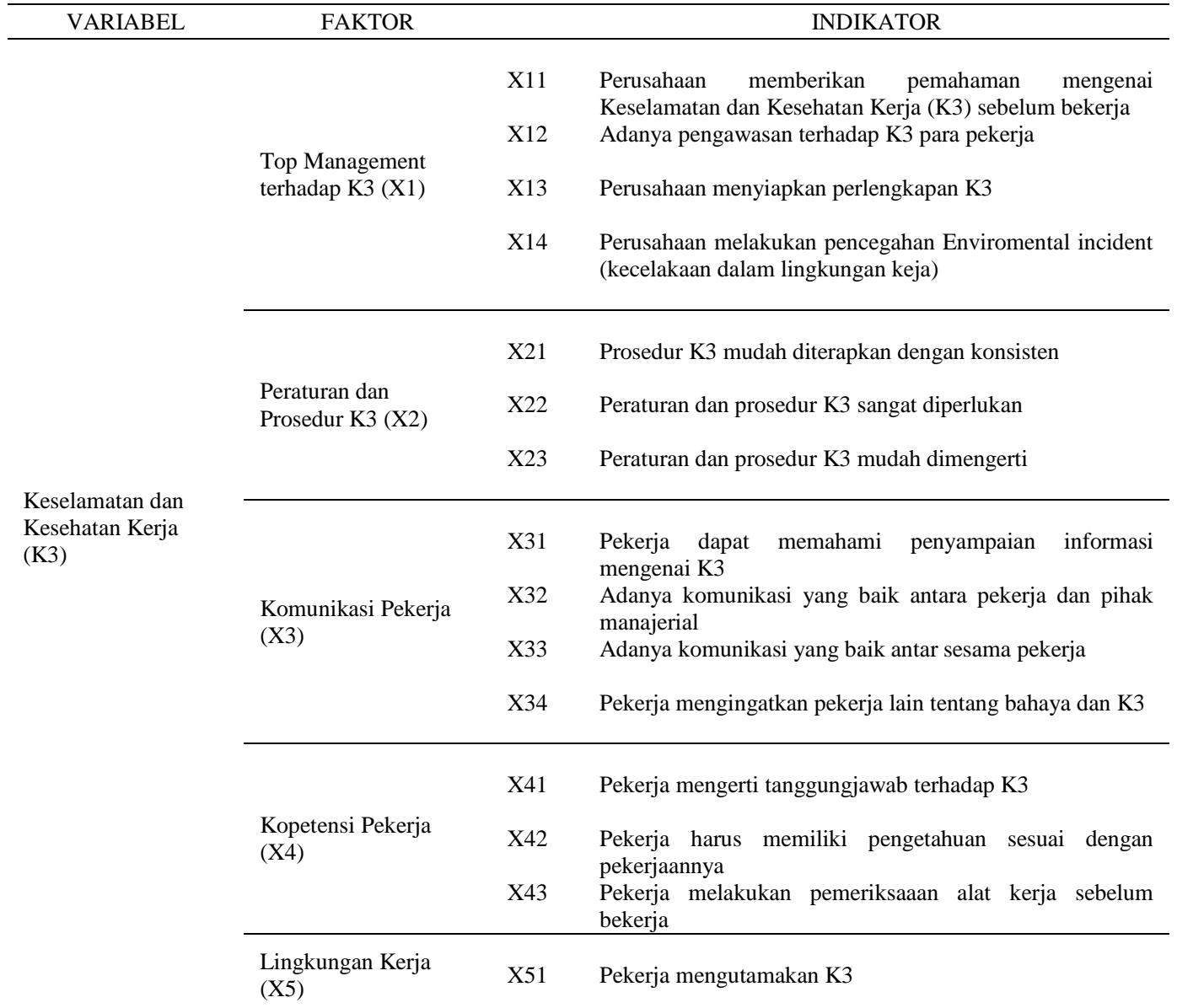




\begin{tabular}{|c|c|c|}
\hline & $\begin{array}{l}\mathrm{X} 52 \\
\mathrm{X} 53\end{array}$ & $\begin{array}{l}\text { Pekerja puas dengan keamanan lingkungan kerja (alat } \\
\text { pengaman, kebersihan, dan pencahayaan) } \\
\text { Pembuangan limbah sesuai tempatnya/ house kepping }\end{array}$ \\
\hline \multirow{4}{*}{ Kesehatan Kerja (X6) } & X61 & Perusahaan cepat dalam menangani kasus kecelakaan di \\
\hline & $\mathrm{X} 62$ & $\begin{array}{l}\text { Pekerja wajib memakai APD (sepatu, helm, rompi, dan } \\
\text { sarung tangan) pada saat bekeria }\end{array}$ \\
\hline & X63 & $\begin{array}{l}\text { Perusahaan memberikan asuransi kesehatan kepada setiap } \\
\text { pekerja }\end{array}$ \\
\hline & X64 & $\begin{array}{l}\text { Pekerja mampu melakukan pekerjaannya dengan cara } \\
\text { yang aman }\end{array}$ \\
\hline \multirow{4}{*}{ Kinerja Pekerja (X7) } & $\mathrm{X} 71$ & Tidak adanya kesalahan dalam melakukan pekerjaan \\
\hline & $\mathrm{X} 72$ & Pekerja hadir (masuk) sesuai dengan jadwal kerja \\
\hline & $\mathrm{X} 73$ & $\begin{array}{l}\text { Hasil pekerjaan memenuhi spesifikasi dan kriteria yang } \\
\text { ditentukan }\end{array}$ \\
\hline & X74 & Tidak adanya kecelakaan kerja di lingkungan kerja \\
\hline
\end{tabular}

\subsection{Analisis Data}

Pada penelitian ini untuk menganalisis data dengan menggunakan metode analisis kuantitatif. Metode analisis kuantitatif merupakan metode yang digunakan untuk menyajikan data dalam bentuk angka. Agar jawaban responden dapat diukur maka jawaban responden diberi skor. Dalam pemberian skor digunakan skala likert.

Tabel 2. Skala Likert

\begin{tabular}{lc}
\hline \multicolumn{1}{c}{ Pernyataan } \\
\hline \multicolumn{1}{c}{ Positif } & Nilai \\
\hline Sangat Setuju (SS) & 5 \\
Setuju (S) & 4 \\
Ragu-Ragu (RR) & 3 \\
Tidak Setuju (TS) & 2 \\
Sangat Tidak Setuju (STS) & 1 \\
\hline
\end{tabular}

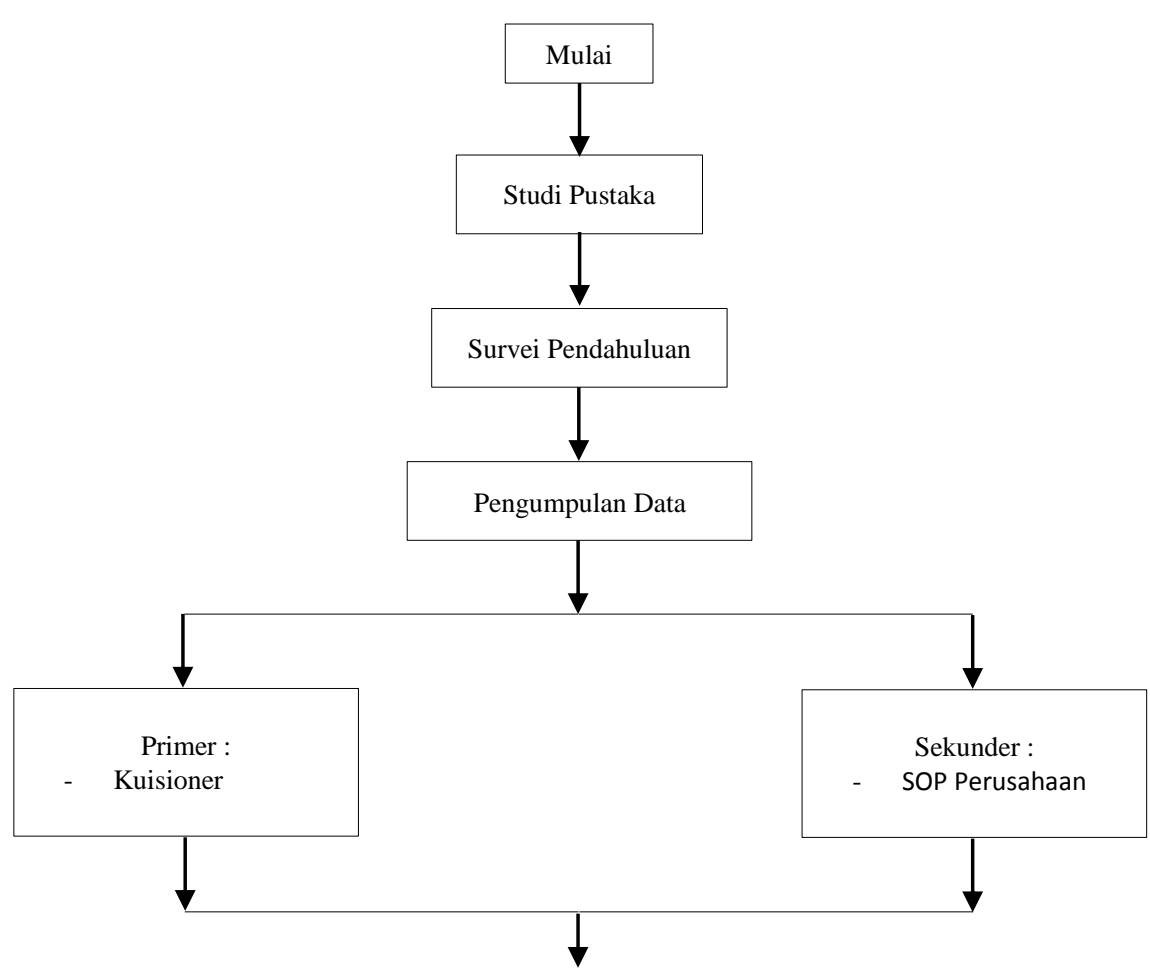




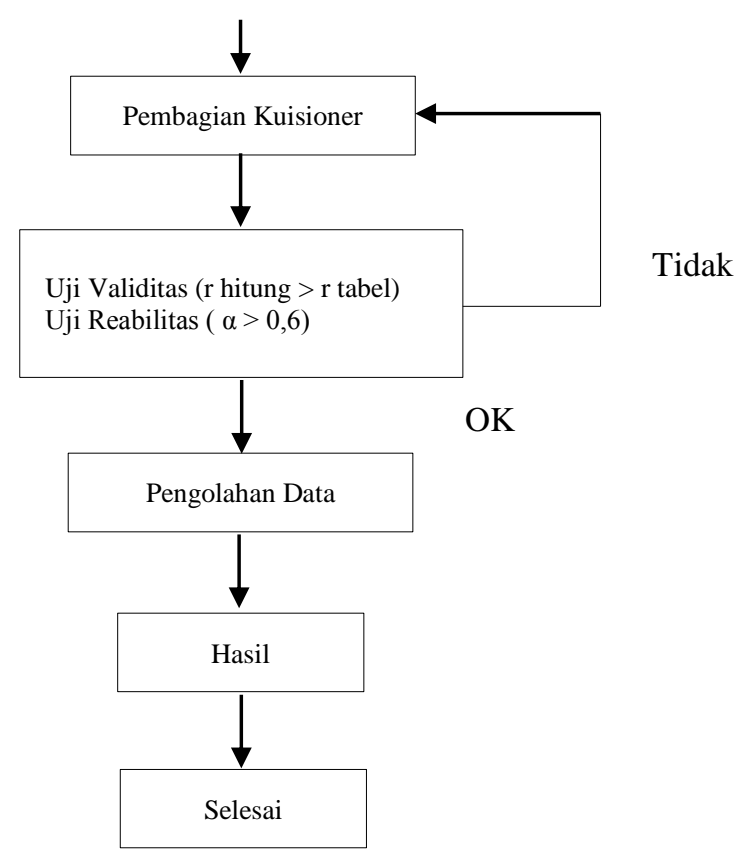

Gambar 2. Bagan Alir Penelitian

\section{HASIL DAN PEMBAHASAN}

\subsection{Data Hasil Kuisioner}

$$
\mathrm{n} \quad=\frac{N}{\left(1+\left(N \times e^{2}\right)\right)} \quad=\frac{94}{\left(1+\left(94 \times 0,1^{2}\right)\right)}=48 \text { sampel }
$$

Dimana :
$\mathrm{n} \quad$ = jumlah sampel
$\mathrm{N}$ = jumlah populasi (pekerja buruh sub pembesian)
$\mathrm{e} \quad=$ persen kelonggaran ketidaktelitian karena kesalahan pengambilan yang masih ditolerir, yaitu 0.1 $\%$ atau $10 \%$

Dari 94 populasi didapat sampel sebanyak 48. Kuisioner berisi 25 pernyataan yang kemudian dilakukan uji validitas dan uji reabilitas.

\subsection{Hasil Uji Validitas dan Reabilitas}

1. Uji Validitas

Tabel 4. Hasil Uji Validitas

\begin{tabular}{cccc}
\hline $\begin{array}{c}\text { No. Item } \\
\text { Instrumen }\end{array}$ & $\begin{array}{c}\mathrm{r} \\
\text { Hitung }\end{array}$ & $\begin{array}{c}\mathrm{r} \\
\text { Tabel }\end{array}$ & Keterangan \\
\hline 1 & 0,709 & 0,291 & Valid \\
2 & 0,702 & 0,291 & Valid \\
3 & 0,763 & 0,291 & Valid \\
4 & 0,585 & 0,291 & Valid \\
5 & 0,783 & 0,291 & Valid \\
6 & 0,675 & 0,291 & Valid \\
7 & 0,731 & 0,291 & Valid \\
8 & 0,603 & 0,291 & Valid \\
9 & 0,819 & 0,291 & Valid \\
10 & 0,789 & 0,291 & Valid \\
11 & 0,531 & 0,291 & Valid \\
12 & 0,746 & 0,291 & Valid \\
13 & 0,815 & 0,291 & Valid \\
14 & 0,828 & 0,291 & Valid \\
\hline
\end{tabular}




\begin{tabular}{cccc}
\hline 15 & 0,572 & 0,291 & Valid \\
16 & 0,675 & 0,291 & Valid \\
17 & 0,781 & 0,291 & Valid \\
18 & 0,856 & 0,291 & Valid \\
19 & 0,637 & 0,291 & Valid \\
20 & 0,888 & 0,291 & Valid \\
21 & 0,923 & 0,291 & Valid \\
22 & 0,916 & 0,291 & Valid \\
23 & 0,744 & 0,291 & Valid \\
24 & 0,766 & 0,291 & Valid \\
25 & 0,753 & 0,291 & Valid \\
\hline Sumber : Hasil Analisis IBM SPSS, 2020
\end{tabular}

Berdasarkan hasil uji validitas dari 25 pernyataan menunjukan nilai rHitung > rTabel. Sehingga semua instrumen dalam penelitian ini dapat dikatakan valid.

2. Uji Reabilitas

Tabel 5. Hasil Uji Reabilitas

\begin{tabular}{ccc}
\hline Ket & Cronbach's Alpha & Ket \\
\hline X1 & 0,612 & Reabel \\
X2 & 0,737 & Reabel \\
X3 & 0,617 & Reabel \\
X4 & 0,703 & Reabel \\
X5 & 0,925 & Reabel \\
X6 & 0,853 & Reabel \\
X7 & 0,798 & Reabel \\
\hline Sumber : Hasil Analisis IBM SPSS, 2020 &
\end{tabular}

Hasil tersebut dapat disimpulkan bahwa semua aspek pernyataan tersebut dikatakan reliabel karena nilai Croanbach's alpha lebih dari 0,6.

\subsection{Analisis Pelaksanaan K3}

1. Variabel Top Management (X1)

Tabel 6. Variabel Top Management

\begin{tabular}{cccccc}
\hline Pernyataan & SS & S & RR & TS & STS \\
\hline 1 & 20 & 27 & 0 & 0 & 1 \\
& $(41,67 \%)$ & $(56,25 \%)$ & & & $(2,08 \%)$ \\
2 & 16 & 33 & 0 & 0 & 0 \\
3 & $(33,33 \%)$ & $(68,75 \%)$ & 0 & 0 & 0 \\
& 23 & 16 & 9 & 0 & 0 \\
& $(47,92 \%)$ & $(33,33 \%)$ & $(18,75 \%)$ & 0 &
\end{tabular}

2. Variabel Peraturan dan Proedur K3 (X2)

Tabel 7. Variabel Peraturan dan Proedur K3

\begin{tabular}{cccccc}
\hline Pernyataan & SS & S & RR & TS & STS \\
\hline \multirow{2}{*}{1} & 11 & 32 & 5 & 0 & 0 \\
2 & $(22,92 \%)$ & $(66,67 \%)$ & $(10,42 \%)$ & & \\
& 12 & 36 & 0 & 0 & 0 \\
3 & $(25,00 \%)$ & $(75,00 \%)$ & 0 & & 0 \\
\hline
\end{tabular}

Sumber : Hasil Analisis, 2020 
3. Variabel Komunikasi Pekerja (X3)

Tabel 8. Variabel Komunikasi Pekerja

\begin{tabular}{cccccc}
\hline Pernyataan & SS & S & RR & TS & STS \\
\hline 1 & 9 & 39 & 0 & 0 & 0 \\
2 & $(18,75 \%)$ & $(81,25 \%)$ & & & 0 \\
3 & 25 & 23 & 0 & 0 & 0 \\
4 & $(52,08 \%)$ & $(47,92 \%)$ & & 0 & 0 \\
\hline & 27 & 21 & 0 & & 0 \\
\hline Sumber: Hasil Analisis, 2020 & $(56,25 \%)$ & $(43,75 \%)$ & 2 & 0 &
\end{tabular}

4. Variabel Kopetensi Pekerja (X4)

Tabel 9. Variabel Kopetensi Pekerja

\begin{tabular}{cccccc}
\hline Pernyataan & SS & S & RR & TS & STS \\
\hline 1 & 16 & 32 & 0 & 0 & 0 \\
2 & $(33,33 \%)$ & $(66,67 \%)$ & 0 & 0 & 1 \\
& 12 & 35 & 0 & & $(2,08 \%)$ \\
3 & $(25 \%)$ & $(72,92 \%)$ & & 0 & 0 \\
\hline Sumber : Hasil Analisis, 2020 & $(50 \%)$ & $(50 \%)$ & 0 & &
\end{tabular}

5. Variabel Lingkungan Kerja (X5)

Tabel 10. Variabel Lingkungan Kerja

\begin{tabular}{cccccc}
\hline Pernyataan & SS & S & RR & TS & STS \\
\hline 1 & 18 & 30 & 0 & 0 & 0 \\
2 & $(37,50 \%)$ & $(62,50 \%)$ & & & \\
2 & 18 & 30 & 0 & 0 & 0 \\
3 & $(37,50 \%)$ & $(63 \%)$ & & 0 & 1 \\
& 18 & 29 & 0 & 0 & $(2,08 \%)$ \\
\hline
\end{tabular}

Sumber : Hasil Analisis, 2020

6. Variabel Kesehatan Kerja

Tabel 11. Variabel Kesehatan Kerja

\begin{tabular}{cccccc}
\hline Pernyataan & SS & S & RR & TS & STS \\
\hline 1 & 20 & 27 & 0 & 0 & 1 \\
& $(41,67 \%)$ & $(56,25 \%)$ & & & $(2,08 \%)$ \\
2 & 20 & 28 & 0 & 0 & 0 \\
& $(41,67 \%)$ & $(58,33 \%)$ & 0 & 0 & 1 \\
3 & 29 & 18 & 0 & & 1 \\
& $(60,42 \%)$ & $(37,50 \%)$ & $08 \%)$ \\
4 & 22 & 25 & 0 & 0 & $(2,08 \%)$ \\
\hline
\end{tabular}

7. Variabel Kinerja Pekerja

Tabel 12. Variabel Kinerja Pekerja

\begin{tabular}{cccccc}
\hline Pernyataan & SS & S & RR & TS & STS \\
\hline 1 & 17 & 25 & 6 & 0 & 0 \\
& $(35,42 \%)$ & $(52,08 \%)$ & $(12,50 \%)$ & & 0 \\
2 & 15 & 33 & 0 & 0 & 0 \\
3 & $(31,25 \%)$ & $(68,75 \%)$ & & 0 & 0 \\
\hline
\end{tabular}

CIVeng Vol.1, No.2, Juli 2020 : 69 76 


\begin{tabular}{cccccc}
\hline 4 & 14 & 25 & 9 & 0 & 0 \\
\hline Sumber: Hasil Analisis, 2020 & & & & \\
& $(29,17 \%)$ & $(52,08 \%)$ & $(18,75 \%)$ & 0 &
\end{tabular}

Sumber: Hasil Analisis, 2020

\section{KESIMPULAN}

Pelaksanaan K3 pada Proyek Pembangunan Gedung K Universitas Muhammadiyah Purwokerto sebagian sudah dilaksanakan sesuai dengan SOP perusahaan $(86,28 \%)$. Hasil tersebut didukung oleh beberapa faktor yaitu top management (85\%), faktor peraturan dan prosedur K3 $(83,19 \%)$, faktor komunikasi pekerja $(87,81 \%)$, faktor kopetensi pekerja $(86,81 \%)$, faktor lingkungan kerja $(87,08 \%)$, faktor kesehatan kerja $(88,54 \%)$, dan faktor kinerja pekerja $(85,52 \%)$.

\section{DAFTAR PUSTAKA}

[1] A.D, Austen dan R.H. Neale. 1991. Manajemen Proyek Konstruksi. Jakarta:PPM

[2] Ahmad, Rosli. 2008. Best Practices In Safety Management for Conventional Civil Construction Industry in Malaysia. Penerbit: Universiti Teknologi Malaysia.

[3] Anonim. 2014. Peraturan Menteri Pekerjaan Umum Nomor : 09/PER/M/2008 tentang Pedoman Sistem Manajemen Keselamatan Dan Kesehatan Kerja (Smk3) Konstruksi Bidang Pekerjaan Umum.

[4] .1970. Undang-undang no.1 tahun 1970 tentang Keselamatan Kerja.

[5] . 1980. Peraturan Menteri Tenaga Kerja dan Transmigrasi Nomor Per.02/MEN/1980 tentang pemeriksaan kesehatan tenaga kerja dalam penyelenggaraan keselamtan kerja.

[6] 1986. Surat Keputusan Bersama Menteri Tenaga Kerja dan Menteri Pekerjaan Umum Nomor: 174/MEN/1986 \& 104/KPTS/1986 tentang Keselamatan dan Kesehatan Kerja pada Tempat Kegiatan Konstruksi.

[7] .1992. Undang-undang no.23 tahun 1992 pasal 23 tentang Kesehatan Kerja.

[8] .1992. Undang-undang no.3 tahun 1992 tentang jaminan sosial tenaga kerja (Jamsostek).

[9] .1993. Peraturan Menteri Tenaga Kerja Nomor.04/MEN/1993 tentang jaminan kecelakaan kerja.

[10] Argama, R. 2006. Kesehatan dan Keselamatan Kerja Sebagai Komponen Jamsostek. LPFH Universitas Indonesia.

[11] Dewi, Rijuna. 2006. Pengaruh Keselamatan dan Kesehatan Kerja Terhadap Kinerja Karyawan pada PT. Ecogreen Oleochemicals Medan Plant. Skripsi. Fakultas Ekonomi USU.

[12] Endroyo. Bambang. 2006. Peranan Manajemen K3 Dalam Pencegahan Kecelakaan Kerja Konstruksi. Teknik Sipil Unika Soegijapranata. Semarang.

[13] Ervianto, I.W. 2005. Manajemen Proyek Konstruksi. Andi Offset. Yogyakarta.

[14] Ghozali, Imam. 2013. Aplikasi Analisis Multivariate dengan Program IBM SPSS 21. Cetakan ke VII. Semarang : Badan Penerbit Universitas Diponegoro.

[15] Husen. Abrar. 2009. Manajemen Proyek. Andi Offset. Yogyakarta.

[16] Husni, Lalu. 2003. Hukum Ketenagakerjaan Indonesia. Jakarta: PT Raja Grafindo Persada.

[17] Indah, Aryati. Evaluasi Penerapan Keselamatan Dan Kesehatan Kerja (K3) Pada Proyek Bangunan Gedung Di Kabupaten Cirebon. Jurnal Teknik Sipil \& Perencanaan 19 (1) (2017) hal 1-8.

[18] Kementrian Pendidikan dan Kebudayaan Republik Indonesia. Keselamatan Kerja Dan Kesehatan Lingkungan. Jakarta, 2013.

[19] N. A. Eka., Sugiyarto, H. F. Sri. Analisis Pengaruh Kesehatan Dan Keselamatan Kerja (K3) Terhadap Kinerja Pekerja Konstruksi Pada Proyek Pembangunan Fly Over Palur. E-Jurnal Matriks Teknik Sipil.

[20] N. N. Arifa. 2018. Analisa Manajemen Risiko Keselamatan Dan Kesehatan Kerja (K3) Pada Pembangunan Gedung Fakultas Pertanian Universitas Brawijaya. Skripsi. Malang : Fakultas Teknik Universitas Brawijaya.

[21] Ridley, John. 2008. Ikhtisar Kesehatan \& Keselamatan Kerja. Edisi Ketiga. Jakarta : Erlangga.

[22] Riduwan, M. 2011. Skala Pengukuran Variabel-Variabel Penelitian.Bandung: Alfabeta.

[23] Sanjaya, dkk. Analisis Penerapan Keselamatan Dan Kesehatan Kerja (K3) Pada Proyek Konstruksi Gedung Di Kabupaten Klungkung Dan Karangasem. Jurnal Ilmiah Elektronik Infrastruktur Teknik Sipil.

[24] Saputri, yuliana. 2018. Analisis Pelaksanaan Keselamatan Dan Kesehatan Kerja(K3) Pada Proyek Cilacap Expansion $1 x 1000$ Mw Cfspp. Skripsi. Purwokerto: Fakultas Teknik dan Sains UMP.

[25] Schuler, Randall S. dan Susan E. Jackson (Alih Bahasa : Abdul Rasyid).1999. Manajemen Sumber Daya Manusia: Menghadapi Abad Ke-21. Jakarta: Erlangga.

[26] Simanjuntak, Payman J. 2005. Manajemen dan Evaluasi Kerja. Jakarta: Lembaga Penerbit Fakultas Ekonomi UI.

[27] Sugiyono. 2009. Memahami Penelitian Kualitatif. Bandung: Alfabeta.

[28] Suma'mur. 2009. Hiegiene Perusahaan dan Keselamatan Kerja. Jakarta : CV. Sagung Seto.

[29] Tarwaka, 2017. Keselamatan dan Kesehatan Kerja Manajemen dan Implementasi K3 di tempat kerja. Surakarta: Harapan Press. 
